\title{
EVALUATION OF INSTRUMENTAL ACTIVITIES OF DAILY LIVING (IADL) IN PATIENTS WITH SYSTEMIC
} LUPUS ERYTHEMATOSUS (SLE).

Marcela Braga Sampaio (Universidade Estadual do Ceará (UECE), Fortaleza, CE, Brasil), Lísia Laiane Abreu Gomes Loiola (Universidade de Fortaleza (UNIFOR), Fortaleza, CE, Brasil), Mariana Macedo Militão Mendonça (Universidade de Fortaleza (UNIFOR), Fortaleza, CE, Brasil), Marina Isidório Cruz Macêdo (Universidade de Fortaleza (UNIFOR), Fortaleza, CE, Brasil), Kirla Wagner Poti Gomes (Hospital Geral de Fortaleza (HGF), Fortaleza, CE, Brasil), Rejane Maria Rodrigues de Abreu Vieira (Hospital Geral de Fortaleza (HGF), Universidade Estadual do Ceará (UECE) e Universidade de Fortaleza (UNIFOR), Fortaleza, CE, Brasil)

\section{BACKGROUND}

The Systemic Lupus Erythematosus (SLE) as a chronic inflammatory disease, which symptoms can occur in several organs, can often cause several limitations to patients, impairing their functional capacity. The objective of this study was to evaluate the ability to perform the instrumental activities of daily living (IADLs) of patients with SLE treated at the outpatient clinic of a referral hospital in Fortaleza.

\section{MATERIALS AND METHODS}

Quantitative cross-sectional study based on the data collected through a validated version of the Instrumental Activities of Daily Living Scale (IADL) developed by Lawton and Brody and adapted to the Brazilian context, which scores range from 5 to 21 points, with index 5 indicating a total dependence, index between 5 and 20 indicates partial dependence and the index equal to 21 indicates independence. The Ethical Committee approved the study of research, and the participants filled the free and clarified consent term (TCLE).

\section{RESULTS}

We interviewed 48 patients with SLE through The majority of patients interviewed were female (95.8\%), with a mean age of $39.35 \pm 13.09$. The mean score of the Lawton and Brody Scale was $18.35 \pm 1.91$. Regarding the ability to perform the AIVDs, $89.6 \%$ of the patients interviewed classified as partial dependents. About the time of diagnosis of SLE, the mean value found was $8.79 \pm 6.11$ years, a large part $(41.7 \%)$ in the interval of 7 to 12 years of diagnosis. In addition, $56.2 \%$ of the patients presented other pathologies associated with SLE, such as fibromyalgia, hypothyroidism, and dyslipidemia.

\section{CONCLUSION}

Patients with SLE, for the most part, are partially dependent on their ability to perform AIVDs when evaluated by the Lawton and Brody Scale. 